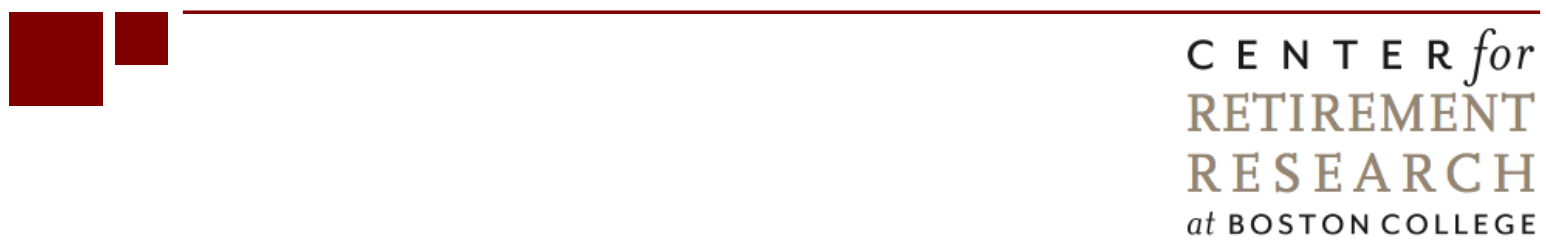

\title{
THE CAUSES AND CONSEQUENCES OF FINANCIAL FRAUD AMONG OLDER AMERICANS
}

\author{
Keith Jacks Gamble, Patricia Boyle, Lei Yu, and David Bennett \\ CRR WP 2014-13 \\ Submitted: July 2014 \\ Released: November 2014

\begin{abstract}
Center for Retirement Research at Boston College
Hovey House

140 Commonwealth Ave

Chestnut Hill, MA 02467
\end{abstract} \\ Tel: 617-552-1762 Fax: 617-552-0191 \\ http://crr.bc.edu
}

Keith Jacks Gamble is an assistant professor of finance at DePaul University. Patricia Boyle is a neuropsychologist with the Rush Alzheimer's Disease Center and an associate professor at Rush University Medical Center. Lei Yu is a statistician with Rush Alzheimer's Disease Center and an assistant professor of neurological sciences at Rush University Medical Center. David Bennett is director of the Rush Alzheimer's Disease Center and the Robert C. Borwell Professor of Neurological Sciences at Rush University Medical Center. The research reported herein was performed pursuant to a grant from the U.S. Social Security Administration (SSA) funded as part of the Retirement Research Consortium. The opinions and conclusions expressed are solely those of the authors and do not represent the opinions or policy of SSA, any agency of the federal government, DePaul University, Rush Alzheimer's Disease Center, Rush University Medical Center, or Boston College. Neither the United States Government nor any agency thereof, nor any of their employees, makes any warranty, express or implied, or assumes any legal liability or responsibility for the accuracy, completeness, or usefulness of the contents of this report. Reference herein to any specific commercial product, process or service by trade name, trademark, manufacturer, or otherwise does not necessarily constitute or imply endorsement, recommendation or favoring by the United States Government or any agency thereof.

(C) 2014, Keith Jacks Gamble, Patricia Boyle, Lei Yu, and David Bennett. All rights reserved. Short sections of text, not to exceed two paragraphs, may be quoted without explicit permission provided that full credit, including (C) notice, is given to the source. 


\title{
About the Steven H. Sandell Grant Program
}

This paper received funding from the Steven H. Sandell Grant Program for Junior Scholars in Retirement Research. Established in 1999, the Sandell program's purpose is to promote research on retirement issues by scholars in a wide variety of disciplines, including actuarial science, demography, economics, finance, gerontology, political science, psychology, public administration, public policy, sociology, social work, and statistics. The program is funded through a grant from the Social Security Administration (SSA). For more information on the Sandell program, please visit our website at: http://crr.bc.edu/about-us/grantprograms/stevenhsandell-grant-program-2/ send e-mail to crr@bc.edu, or call (617) 552-1762.

\section{About the Center for Retirement Research}

The Center for Retirement Research at Boston College, part of a consortium that includes parallel centers at the University of Michigan and the National Bureau of Economic Research, was established in 1998 through a grant from the Social Security Administration. The Center's mission is to produce first-class research and forge a strong link between the academic community and decision-makers in the public and private sectors around an issue of critical importance to the nation's future. To achieve this mission, the Center sponsors a wide variety of research projects, transmits new findings to a broad audience, trains new scholars, and broadens access to valuable data sources.

\author{
Center for Retirement Research at Boston College \\ Hovey House \\ 140 Commonwealth Avenue \\ Chestnut Hill, MA 02467 \\ phone: 617-552-1762 fax: 617-552-0191 \\ e-mail: crr@bc.edu \\ crr.bc.edu
}

Affiliated Institutions:

The Brookings Institution

Massachusetts Institute of Technology

Syracuse University

Urban Institute 


\begin{abstract}
Financial fraud is a major threat to older Americans, and this problem is expected to grow as the baby boom generation retires and more retirees manage their own retirement accounts. We use a unique dataset to examine the causes and consequences of financial fraud among older Americans. First, we find that decreasing cognition is associated with higher scam susceptibility scores and is predictive of fraud victimization. Second, overconfidence in one's financial knowledge is associated with fraud victimization. Third, fraud victims increase their willingness to take financial risks relative to propensity-matched non-victims.
\end{abstract}




\section{Introduction}

James Poterba’s Richard T. Ely Lecture (2014) at the annual meeting of the American Economic Association highlights several of the challenges and threats to the retirement security of the aging U.S. population. Longer life-expectancy means prospective retirees must save more or retire later. The uncertainty of future health care costs looms large, as well as the uncertainty of future investment returns. Increasingly individuals rather than institutions are tasked with making financial decisions in this challenging environment. Agarwal et al. (2009) demonstrate that financial decision making ability peaks in the 50s and declines during typical retirement ages. Declining cognition presents a major challenge for current and future retirees. Gamble et al. (2014) show that declining cognition is associated with declining financial literacy and an increased propensity to seek help with managing one's finances. These factors perhaps make affected seniors more vulnerable to financial fraud. This study tests the hypothesis that decreased cognition makes one more vulnerable to being victimized by financial fraud. We also test the hypothesis that overconfidence in one's own financial knowledge plays a role in making one susceptible to financial fraud. In addition we examine if being victimized by fraud impacts future willingness to take on financial risk.

Blanton (2012) reports remarkable statistics demonstrating the rise of financial fraud in the United States. Fraud complaints have increased fivefold in the past decade, according to the Federal Trade Commission; over 1 million complaints were filed in 2010. The number of enforcement actions that the Securities and Exchange Commission logged against investment advisors and companies reached 146 in 2011, a new record. The plague of financial fraud is particularly harmful for older Americans, who are the most commonly victimized segment of the population. The 2012 Senior Financial Exploitation Study ${ }^{1}$ conducted by the Certified Financial Planner (CFP) Board of Standards, Inc., found that 56 percent of CFP professionals had an older client who had been financially exploited, and the average estimated loss was \$50,000 per victim. Retirees are particularly at risk for financial scams. After decades of saving for retirement, many have reached their peak level of wealth, which attracts scammers. Furthermore, the shift from pension plans to individual retirement accounts puts individuals in charge of managing more of their own financial assets, thus enabling bigger frauds.

\footnotetext{
${ }^{1}$ Results available for download at http://www.cfp.net/docs/news-events---supporting-documents/senior-americansfinancial-exploitation-survey.pdf?sfvrsn $=0$
} 
Little is known about why many older Americans are susceptible to financial fraud and what factors contribute to their vulnerability. There is a lack of available data that include the required information about fraud victimization along with the personal characteristics of victims and those not victimized. This research study utilizes the rich dataset collected by the Rush University Alzheimer's Disease Center's Memory and Aging Project, which provides a notable exception. This dataset includes yearly self-reports of fraud victimization along with demographic characteristics and measures of cognition, financial literacy, and decision making. Our analysis includes 787 participants without dementia, and 93 (12 percent) of these seniors report being recently victimized by fraud. We use this dataset to test two hypotheses concerning the causes of fraud victimization and one concerning the consequences.

We hypothesize that decreased cognition predicts increased vulnerability to fraud. We use two measures of vulnerability. The first, which we call a score of susceptibility to scam, employs a set of six survey questions designed to capture actions and beliefs that are consistent with providing an opportunity for scammers. For example, participants are asked if they have difficulty ending a phone call and if they believe persons over the age of 65 are often targeted by con artists. Indeed, we find that a decrease in cognitive slope predicts a higher susceptibility to scam score. Our second measure of fraud vulnerability is self-reported fraud victimization. We find that a one-standard deviation decrease in cognitive slope is estimated to increase odds of fraud victimization by 33 percent.

Our second hypothesis is that overconfidence in one's financial knowledge is a significant predictor of the odds of becoming a victim of financial fraud. Our measure of overconfidence combines participants' answers to a set of standard financial literacy questions with their confidence in each answer. Overconfidence is defined as getting the literacy questions wrong while thinking that they are right. We find that overconfidence is a significant risk factor for becoming a victim of financial fraud. A one standard deviation increase in overconfidence increases the odds of falling victim to fraud by 26 percent. Financial knowledge, not just general knowledge, protects against fraud: years of education is not a significant predictor of the likelihood of being victimized by fraud.

Overconfidence is known to be a significant factor in explaining the poor investment decision making of households. For example, Barber and Odean (2000) show that households lose money by frequently trading stocks, and Barber and Odean (2001) connect this behavior to 
overconfidence. Goetzmann and Kumar (2008) show that investors who are overconfident diversify their investment portfolio less, thus taking on more risk than is necessary to achieve the same level of expected return. The present study contributes to this literature by showing that overconfidence is a significant risk factor for becoming a victim of financial fraud.

Our third hypothesis concerns the impact of financial fraud on victims’ willingness to take financial risk. Thaler and Johnson (1990) demonstrate that after taking losses many decision makers show an increased willingness to take on risk in an effort to break even. Indeed, we find that financial fraud victims show an increased willingness to take risk relative to those not victimized. We employ two measures of willingness to take financial risk. First, fraud victims report an increased assessment of their lifetime willingness to take on financial risk relative to the decline in non-victims' assessment of their lifetime willingness. Second, fraud victims become increasingly willing to accept a gamble with an equally likely chance of doubling one's annual income as cutting it by 10 percent. Both of these results are robust to propensity-matched comparisons of fraud victims to non-victims.

The remainder of this paper proceeds as follows. Section 2 describes the data and our procedures. Section 3 contains the results. Section 4 concludes.

\section{Data and Procedure}

Data Description and Construction of Measures. The dataset analyzed in this paper is collected by the Rush Memory and Aging Project (MAP), an ongoing longitudinal study of aging (Bennett et al. (2005). Beginning in 1997, the project has enrolled more than 1,500 participants from the Chicago metropolitan area who have completed the baseline evaluation. Participants in the project are provided risk factor assessments and clinical evaluations each year, which include medical history, neurological, and neuropsychological examinations. MAP collects demographic information for each participant, including age, sex, and education.

Cognition is measured each year in MAP using a battery of the same 19 tests. The names of each specific test are included in Appendix A. These tests examine five domains of cognition: episodic memory, semantic memory, working memory, perceptual speed, and visuospatial ability. Episodic memory is the memory of specific events, whereas semantic memory refers to the knowledge of concepts. Working memory is the ability to store and process transitory information. Perceptual speed is the ability to process information quickly and make mental 
comparisons. Visuospatial ability is about understanding visual representations and the spatial relationships among objects. The results of these cognition tests are compiled into a global cognitive function score that equals the average z-score among the 19 tests. For each test, the raw scores are converted to z-scores using the baseline mean and standard deviation of the entire MAP cohort. A decision-making assessment was added to the project in 2010. The exact wording of the questions in the decision-making assessment that are used in this study are provided in Appendix B. MAP and the decision-making substudy were approved by the Institutional Review Board of Rush University Medical Center.

The decision making assessment includes a question asking participants whether or not in the past year they were victimized by financial fraud or have been told they were a victimized by financial fraud. We identify fraud victims as those participants who answered affirmatively in any of their yearly assessments. Naturally, this self-report measure is imperfect since participants who are fraud victims may not realize that they have been victimized and may report a false negative answer. In addition, a participant may be aware of being victimized by fraud but may choose to hide it. Finally, a participant may have incorrectly perceived a loss as fraudulent when it is not. We include data only from participants not diagnosed with dementia at the time of the evaluation using the procedure specified by Bennett et al. (2005). The reason for the exclusion is that participants diagnosed with dementia have difficulty answering recall questions, including the question required to identify fraud victims.

The decision-making questionnaire includes six questions to measure each participant's susceptibility to scams. The first five questions ask participants to what extent they agree with five statements on a seven-point scale from strongly agree to strongly disagree. Three statements concern a participant's vulnerability to phone calls from a scammer. One states that if something sounds too good to be true, then it probably is. Another states that people over the age of 65 are often targeted by con artists. The sixth item in the susceptibility to scams measure is whether or not the participant is enrolled in the national do-not-call registry. The first five responses are each scored from one to seven to match the strength of the response to the question. For example, a response of strongly agree to a statement indicating vulnerability scores a seven, while a response of strongly disagree to the statement scores a one. Not being enrolled in the donot-call registry scores a seven, while being enrolled scores a one. The susceptibility to scams measure is calculated as the sum of scores for the six questions. 
The decision making questionnaire also includes nine standard financial literacy questions to test participants' financial knowledge. The first two questions concern the FDIC and its role in the financial system. Then participants are asked what investments mutual funds hold and how bond prices react to interest rates. The final five financial knowledge questions are in true-false format. The first two ask about the benefit of diversification and whether or not an older person should hold riskier investments than a younger person. The final three ask about paying off credit card debt, the value of frequent stock trading, and the average historical return of stocks relative to bonds.

Each financial knowledge question includes a follow up question, immediately after, which asks for the participant's confidence in her answer to the previous knowledge question. Confidence in each answer is assessed on a four-point scale from extremely confident to not at all confident. We measure financial knowledge by counting the number of correct answers given to the nine financial literacy questions. We measure confidence in financial knowledge by summing the scores to each confidence question with extremely confident scored as a 3, fairly confident as a 2 , a little confident as a 1 , and not at all confident as a 0 . We measure overconfidence in financial knowledge by summing the scores to the confidence questions for which the participant got the associated financial knowledge question wrong. Thus, overconfidence is measured as a combination of poor financial knowledge and an unawareness of this lack of knowledge. A participant who scores low on financial knowledge is not overconfident if she reports being not at all confident in her answers.

We use two types of questions for assessing each participant's inclination to take on financial risk. The first risk-taking question asks each participant to report her lifetime willingness to take financial risks on a 10-point scale, from not at all willing (1) to completely willing (10). The second assessment of risk preferences asks participants if they would be willing to take on an investment opportunity that would double their annual income with a 50 percent probability and cut it by $\mathrm{X}$ percent with a 50percent probability, where $\mathrm{X}$ is replaced by 10 percent, 20 percent, 30 percent, and 50 percent in successive questions. Because so few participants were willing to accept the 30 percent and 50 percent annual income loss gambles, we do not include these in our tabulated analysis. Only 5 percent of participants were willing to accept the 30 percent gamble, and only 1 percent were willing to accept the 50 percent gamble. 


\section{Description of Subsamples and Methods}

Cognitive Slope Sample. Our first hypotheses are that declining cognition is predictive of susceptibility to scams and fraud incidence. To test these hypotheses, we use the panel of participants who began participating in MAP prior to the decision-making substudy and subsequently completed at least one decision-making questionnaire. For these participants, a time series of yearly cognition scores are available from the time of their enrollment, which varies across participants. For each participant with more than one cognition score, we run a linear regression of her cognition scores on her age at the time of testing, and we use the estimated slope coefficient as our measure of cognitive slope. There are data available on 398 such participants who have an average of 6.23 cognition scores, with a minimum of two scores and a maximum of 15 scores. There are many participants (187, or 47 percent) who have positive cognitive slopes due to the practice effect of taking the same cognitive tests each year. Because our focus is on participants with decreasing cognitive ability, we conduct further analysis on this subset of 211 participants, which we term our cognitive slope sample.

To test the hypothesis that declining cognition is predictive of susceptibility to scams, we regress each participant's susceptibility to scam score from her first decision-making questionnaire on her cognitive slope measure computed using only scores prior to the first decision-making questionnaire. We use a logistic regression for the hypothesis that declining cognition is predictive of fraud incidence, since the later variable is a limited dependent variable. Our hypotheses predict a negative coefficient on cognitive slope. We check the robustness of these results by including age, sex, and education as control variables in additional regressions.

Overconfidence Sample. Our next hypothesis concerning the causes of financial fraud is that overconfidence in one's financial knowledge is associated with fraud victimization. For this hypothesis test, we use data on all participants in the decision-making substudy with at least one survey conducted when the participant was not diagnosed with dementia. There are 787 such participants, which we term the overconfidence sample. We test the hypothesis with a logistic regression of fraud victimization on each participant's overconfidence score from her first decision-making questionnaire. Our hypothesis predicts a positive slope coefficient. We also test whether either of the two components of overconfidence, lack of financial knowledge and high confidence, is associated with fraud victimization by itself. For each test we consider the 
robustness of the results by including age, sex, and education as control variables in additional regressions.

After-Fraud Sample. Our last hypothesis is that being victimized by financial fraud increases the propensity to take on financial risk. To calculate the change from before victimization to after victimization, the fraud victim must not have reported being victimized in the first decision-making survey. This restriction excludes 31 fraud victims from the previous subsample. We compare the changes for fraud victims to the changes for non-victims. The changes for non-victims are calculated from their first decision-making survey to their second. To test the hypothesis we conduct a difference in means test of victims' changes and non-victims changes. We also find a fraud propensity-matched non-victim for each victim and test the difference in their changes for significance in order to better isolate the impact of fraud victimization from the selection effect of being a fraud victim.

\section{Results}

Does negative cognitive slope predict susceptibility to scam and fraud victimization? Table 1 presents summary statistics for the cognitive slope sample. The participants are older Americans, mostly female, and well educated on average. Of the 211 participants with a negative cognitive slope, 21 (10 percent) report recent fraud victimization. The average scam susceptibility score is 21 out of a maximum 42 . The average first cognition measure is 0.34 , which means that the participants in this sample average about one-third of a standard deviation above the mean cognition score of all MAP participants at baseline. The reason for this subsample's average being higher than 0 is that participants diagnosed with dementia (who have very negative cognition scores) have been excluded from this subsample. The average final cognition score before the decision-making substudy began is 0.02 , reflecting the negative cognitive slope in this subsample. The average cognitive slope in the sample is -0.06 with a standard deviation of the slope of 0.08 .

Table 2 presents regression results testing the hypothesis that decreasing cognition predicts scam susceptibility. The results support this hypothesis. A one standard deviation (0.08) decrease in cognitive slope is estimated to increase scam susceptibility by $(-11.811) *(-0.08)=0.94$, or about 21 percent of a standard deviation increase in scam 
susceptibility. This result is statistically significant at the 1 percent level. It is also robust to including age, sex, and education in the regression as control variables. Age is the only demographic among the three found to be statistically significantly associated with scam susceptibility. Each year of age is estimated to increase scam susceptibility by 0.20 . Thus, the effect of a one standard deviation decrease in cognitive slope can be translated as equivalent to the effect of $(0.94 / 0.20)=4.7$ years of aging.

Table 3 presents logistic regression results testing the hypothesis that decreasing cognition predicts fraud incidence. The results weakly support the hypothesis. A one standard deviation decrease in cognitive slope is estimated to increase the odds of fraud victimization by $e^{-0.08(-3.597)}-1=33$ percent. The unconditional odds of recent fraud victimization in this cognitive change sample are $\frac{21}{190}=11$ percent; a one standard deviation increase in overconfidence increases these odds to 15 percent. The statistical significance of this result is only marginal at the 10 percent level. However, the result is robust to including age, sex, and education in the regression as control variables. Again, age is the only demographic control variable of the three found to have a statistically significant effect, which is also at the 10 percent level. Surprisingly, the coefficient on age is negative, indicating that older participants are less likely to report being victimized by fraud. This result is surprising given the previous finding that older participants have higher scam susceptibility scores. One potential explanation of these findings is that older participants may be less likely to admit having been a victim of fraud or may be less likely to be aware of their victimization.

Is overconfidence associated with fraud victimization? Table 4 presents summary statistics for the overconfidence sample. Again, participants in this sample are older Americans, mostly female, and well educated on average. Their average age is 82, and 76 percent are female. They average 15 years of education. About 12 percent (93) of the 787 participants report being recently victimized by financial fraud. These fraud victims exhibit greater overconfidence in their financial knowledge. Fraud victims average an overconfidence score of 4.89 compared to 4.08 for those not victimized. This difference in means is statistically significant at the 5 percent level.

We now test if overconfidence in financial knowledge remains a significant predictor of fraud victimization while controlling for age, sex, and education. Table 5 presents the results of 
logistic regressions with fraud victimization as the binary dependent variable. Overconfidence in financial knowledge remains a significant predictor. The coefficient on overconfidence in the first regression is 0.065 , with statistical significance at the 5 percent level. To examine the economic significance of this coefficient, consider a one standard deviation increase in overconfidence (3.6). This increase in overconfidence increases the estimated odds of fraud victimization by $e^{3.6(0.065)}-1=26$ percent. The unconditional odds of recent fraud victimization in this sample are $\frac{93}{694}=13$ percent; a one standard deviation increase in overconfidence increases these odds to 17 percent. Among the demographic control variables, only age is statistically significant. This result corresponds with the small but statistically significant difference in mean ages between fraud victims and those not victimized. The results of this logistic regression reveal that the age difference does not drive the significant difference in overconfidence between the two groups.

We also test if either of the two components of overconfidence is by itself associated with fraud victimization. Neither financial knowledge nor confidence in this knowledge is. The results in Table 5 show that neither low financial knowledge, nor high confidence in this knowledge are significant predictors even at the 10 percent level of statistical significance. Thus, the prior result for overconfidence is driven by the unique mix of its component parts.

Do fraud victims increase their willingness to take risk? Table 6 presents summary statistics for the after-fraud sample. There are 59 fraud victims in the sample. These victims report a lifetime willingness to take financial risk of 4.76 on average prior to reporting being victimized and a slight increase to 4.84 on average after the fraud. In comparison, the 536 participants in the sample not victimized exhibit a slight decrease in lifetime willingness to take on financial risk from 4.88 to 4.68 . Correspondingly, the proportion of fraud victims willing to accept the 50-50 gamble with the chance to double annual income or cut it by 10 percent increases from 12 percent before the fraud to 29 percent after, a 17 percent increase. In contrast, the percentage of non-victims willing to accept the gamble remains unchanged over the same period. The willingness of both the fraud victims and the non-victims to accept the similar gamble with the possibility of cutting annual income by 20 percent is low, and for both groups this percentage slightly declines. 
Table 7 shows how financial risk-taking propensity changed for both fraud victims and non-victims. Non-victims exhibit a decreased willingness to accept risk. Their assessment of their lifetime willingness to take financial risk dropped on average by 0.198 , which is a statistically significant decline at the 5 percent level. In contrast, fraud victims show a slight 0.085 increase, though this increase is not statistically different from zero. The difference in means tests with unpooled variance does not show a statistically significant difference. Because being a victim of fraud is not random, this difference includes both the impact of fraud on risk taking and a selection effect of the difference in characteristics of fraud victims and those not victimized. To better isolate the impact of fraud from the selection effect, we employ propensity matching of fraud victims to non-victims. We compute fraud propensity scores for each participant in the after-fraud sample using the model developed in the previous subsection of the paper with overconfidence and age as statistically significant predictors of fraud victimization (specifically, model 1 of Table 5). Each fraud victim is matched to the non-victim with the closest fraud propensity score, effectively the non-victim most similar in overconfidence and age. Then we compute the propensity-match difference in financial risk taking changes by subtracting the change of the propensity-matched non-victim from the change in each fraud victim. The average difference of these propensity-matched changes is 0.847 and is statistically significant at the 5 percent level. This result indicates that the impact of fraud is to increase the victim's willingness to take on financial risk.

Further evidence of the impact of fraud on victim's risk taking is evident in the changes in victim's willingness to risk portion of their annual income for a chance to double it. About 17 percent more fraud victims are willing to risk 10 percent of their annual income than before being victimized; this increase is statistically significant at the 1 percent level. In contrast, there is virtually no change in the willingness of non-fraud victims to accept this 10 percent income gamble over the same time period. The difference in mean changes between the two groups is statistically significant at the 5 percent level. Again, we use propensity matching to better isolate the impact of fraud victimization from the selection effect of being of the type that is prone to fraud. The propensity-matched difference in fraud victims’ and matched non-victims' changes in willingness to accept the 10 percent income gamble is 22 percent, which is statistically significant at the 5 percent level. This result provides further evidence that the impact of fraud victimization is an increased propensity to take on risk. 
The increased willingness of fraud victims to take on financial risk does have its limit. Fraud victims are not more willing to take on the 20 percent income gamble after being victimized. In fact, 5 percent fewer victims express a willingness to take on this bigger gamble after being victimized, though this result is not statistically different from zero. The difference in willingness to accept the 20 percent income gamble among non-victims is a slight 1 percent drop, which is also not statistically different from zero. Neither the difference in means nor the propensity-matched difference show significant changes. These results are consistent with fraud victim’s increased willingness to take on risk being limited to moderate gambles.

\section{Conclusion}

This paper identifies two causes of financial fraud among older Americans and one consequence for victims' future decision making. We find that decreasing cognition is predictive of higher susceptibility to a scam and future fraud incidence. Cognitive changes may be evident to those spending time with and caring for affected seniors, and our results show these changes provide a warning sign for fraud vulnerability. In addition, we find that overconfidence in one's financial knowledge is a significant risk factor for seniors becoming a victim of financial fraud. This result makes an important contribution to existing research connecting overconfidence with poor investment decision making. Increasing the financial knowledge of older Americans is likely to help protect them from becoming victims of financial fraud. In cases where increasing financial knowledge is not possible, increasing awareness of one's limitations may help protect against the harmful effects of overconfidence. Finally, this study identifies an increased willingness to take financial risk as a consequence of fraud victimization. This increase in risk acceptance may make victims vulnerable to subsequent exploitation, though our results also show that victims may not be more willing to take on particularly large risks following victimization.

How to protect one's finances from abuse should be an important part of the late life planning of seniors; however, money is often kept out of the conversation with caregivers. The Investor Protection Trust's 2010 Elderly Investment Fraud and Financial Exploitation Study ${ }^{2}$ found that just 2 percent of seniors reported being asked about their ability to manage money by their health care provider. While 19 percent of adult children of senior parents who were in

\footnotetext{
${ }^{2}$ Study results available at http://investorprotection.org/downloads/EIFFE_Survey_Report.pdf
} 
touch with their parent's health care provider had raised concerns about mental comprehension, only 5 percent had raised concerns about the handling of money.

Additional research is needed to inform these conversations and planning. Financial victimization of seniors is a large and growing problem, yet the availability of data to study this problem is very limited. New data sources would allow for additional research needed to better understand the factors that predict fraud victimization and the consequences of it. Additional research is an important first step in designing effective solutions to limit the impact of fraud. 


\section{References}

Agarwal, Sumit, John C. Driscoll, Xavier Gabaix, and David Laibson, 2009, "The Age of Reason: Financial Decisions over the Life-Cycle and Implications for Regulation.” Brookings Papers on Economic Activity 2: 51-117.

Barber, Brad M., and Terrance Odean, 2000, “Trading is Hazardous to our Wealth: The Common Stock Investment Performance of Individual Investors,” Journal of Finance 55: 773-806.

Barber, Brad M., and Terrance Odean, 2001, "Boys Will Be Boys: Gender, Overconfidence, and Common Stock Investment.” Quarterly Journal of Economics 116: 261-292.

Bennett, David A., Julie A. Schneider, Aron S. Buchman, Carlos Mendes de Leon, Julia L. Bienais, and Robert S. Wilson, 2005, “The Rush Memory and Aging Project: Study Design and Baseline Characteristics of the Study Cohort.” Neuroepidemiology 25: 163175.

Blanton, Kimberly. 2012. The Rise of Financial Fraud: Scams Never Change but Disguises Do. Report from the Field. Chestnut Hill, MA: Center for Retirement Research at Boston College.

Boyle, Patricia A., Lei Yu, Aron S. Buchman, David I. Laibson, and David A. Bennett. 2011. "Cognitive function is associated with risk aversion in community-based older persons." BMC Geriatrics 11: 53.

Gamble, Keith Jacks, Patricia A. Boyle, Lei Yu, and David A. Bennett. 2014 (forthcoming). “Aging and Financial Decision Making.” Management Science.

Goetzmann, William N., and Alok Kumar, 2008, “Equity Portfolio Diversification.” Review of Finance 12: 433-463.

Poterba, James M., 2014, “Retirement Security in an Aging Population.” American Economic Review: Papers \& Proceedings 104: 1-30.

Thaler, Richard H., and Eric J. Johnson, 1990, "Gambling with the house money and trying to break even: The effects of prior outcomes on risky choice,” Management Science 36: 643-660. 


\section{Table 1: Summary Statistics for Cognitive Slope Sample}

This table presents summary statistics for the cognitive slope sample. Scam susceptibility is the sum of scores on six survey questions each indicating vulnerability to a fraud on a scale from very low susceptibility (1) to very high susceptibility (7). Fraud incidence is self-reported by the participants. Cognition is a z-score scaled to all participants in the Memory and Aging Project at baseline. Cognitive slope is estimated using a linear regression of a participant's cognitive scores on age. Age and Education are stated in years. Values are reported as means (standard deviation) or percentages.

\begin{tabular}{|c|c|c|}
\hline & $\begin{array}{l}\text { All } \\
\text { Participants }\end{array}$ & Negative Cognitive Slope \\
\hline Participants & 398 & 211 \\
\hline Scam Susceptibility & $20.40(4.32)$ & $20.99(4.51)$ \\
\hline Fraud Incidence & $12 \%$ & $10 \%$ \\
\hline $\begin{array}{l}\text { Number of } \\
\text { Cognition Scores }\end{array}$ & 6.23 (2.39) & $6.70(2.49)$ \\
\hline First Cognition & $0.30(0.44)$ & $0.34(0.42)$ \\
\hline Last Cognition & $0.23(0.59)$ & $0.02(0.61)$ \\
\hline Cognitive Slope & $-0.005(0.10)$ & $-0.060(0.08)$ \\
\hline Age & $83.79(7.62)$ & $85.13(7.15)$ \\
\hline Male & $24 \%$ & $21 \%$ \\
\hline Education & 15.13 (2.99) & $15.16(3.10)$ \\
\hline
\end{tabular}




\section{Table 2: Does cognitive slope predict scam susceptibility?}

This table presents the results of four regressions with scam susceptibility as the dependent variable. Each regression analyzes the subset of participants with a negative cognitive slope. Scam susceptibility is the sum of scores on six survey questions each indicating vulnerability to a fraud on a scale from very low susceptibility (1) to very high susceptibility (7). Age and education are measured in years. Male is an indicator variable that equals one for male participants and zero for female participants.

\begin{tabular}{lllll}
\cline { 2 - 5 } Cognitive Slope & $\mathbf{1}$ & $\mathbf{2}$ & $\mathbf{3}$ & $\mathbf{4}$ \\
\cline { 2 - 5 } Age & $-11.811^{* * *}$ & $-12.023^{* * *}$ & $-11.852^{* * *}$ & $-11.816^{* * *}$ \\
& $(3.606)$ & $(3.421)$ & $(3.611)$ & $(3.612)$ \\
Male & - & $0.199^{* * *}$ & - & - \\
& & $(0.040)$ & & \\
Education & - & - & 0.544 & - \\
\multirow{2}{*}{ Intercept } & - & - & $(0.748)$ & \\
& & - & - & -0.061 \\
& $20.240^{* * *}$ & 3.309 & $20.124^{* * *}$ & $(0.098)$ \\
& $(0.379)$ & $(3.453)$ & $(0.412)$ & $(1.535)$ \\
\hline
\end{tabular}

*** indicates statistical significance at the $1 \%$ level 


\section{Table 3: Does cognitive slope predict fraud incidence?}

This table presents the results of four logistic regressions with fraud victimization as the dependent variable. Each regression analyzes the subset of participants with a negative cognitive slope. Fraud incidence is self-reported by the participants. Age and education are measured in years. Male is an indicator variable that equals one for male participants and zero for female participants.

\begin{tabular}{lllll}
\cline { 2 - 5 } Cognitive Slope & $\mathbf{1}$ & $\mathbf{2}$ & $\mathbf{3}$ & $\mathbf{4}$ \\
\cline { 2 - 5 } Age & $-3.597^{*}$ & $-3.423^{*}$ & $-3.582^{*}$ & $-3.680^{*}$ \\
& $(1.952)$ & $(2.006)$ & $(1.955)$ & $(1.960)$ \\
Male & - & $-0.0573^{*}$ & - & - \\
& & $(0.031)$ & & \\
Education & - & - & -0.090 & - \\
\multirow{2}{*}{ Intercept } & - & - & $(0.587)$ & \\
& & & - & 0.0754 \\
& $-2.470^{* * *}$ & 2.357 & $-2.451^{* * *}$ & $-3.642 * * *$ \\
& $(0.285)$ & $(2.542)$ & $(0.311)$ & $(1.169)$ \\
\hline
\end{tabular}

$*$ and $* * *$ indicate statistically significant at the $10 \%$ and $1 \%$ level respectively 


\section{Table 4: Summary Statistics for the Overconfidence Sample}

This table presents summary statistics for the overconfidence sample as well as for a breakdown of the sample into those participants who experienced fraud and those who did not. Financial Knowledge is measured as the number of the nine financial knowledge questions answered correctly. Confidence in Financial Knowledge is the sum of the confidence scores following each financial knowledge question. Participants report their confidence in their answer after each question on a scale of extremely confident (3), fairly confident (2), a little confident (1), or not at all confident (0). Overconfidence is measured as the sum of the confidence scores for questions answered incorrectly. Age and Education are stated in years. Values are reported as means (standard deviation) or percentages.

\begin{tabular}{|c|c|c|c|}
\hline & $\begin{array}{l}\text { All } \\
\text { Participants } \\
\end{array}$ & $\begin{array}{l}\text { Fraud } \\
\text { Victims }\end{array}$ & $\begin{array}{l}\text { Not Fraud } \\
\text { Victims }\end{array}$ \\
\hline Participants & 787 & 93 & 694 \\
\hline $\begin{array}{l}\text { Overconfidence in } \\
\text { Financial Knowledge }\end{array}$ & $4.18(3.62)$ & $4.89 * *(3.54)$ & $4.08 * *(3.62)$ \\
\hline Financial Knowledge & $6.34(1.74)$ & $6.25(1.57)$ & $6.36(1.76)$ \\
\hline $\begin{array}{l}\text { Confidence in } \\
\text { Financial Knowledge }\end{array}$ & $18.82(5.62)$ & 19.53 (4.96) & $18.73(5.70)$ \\
\hline Age & $81.87(7.80)$ & $\begin{array}{l}78.79 * * * \\
(8.64)\end{array}$ & $82.28 * * *(7.59)$ \\
\hline Male & $24 \%$ & $22 \%$ & $24 \%$ \\
\hline Education & $15.22(3.01)$ & $14.90(3.02)$ & $15.26(3.01)$ \\
\hline
\end{tabular}

** and ${ }^{* * *}$ indicate statistically significant at the $5 \%$ and $1 \%$ level respectively 


\section{Table 5: Predicting Fraud with Overconfidence}

This table presents the results of nine logistic regressions with being a fraud victim as the dependent variable. Financial Knowledge is measured as the number of the nine financial knowledge questions answered correctly. Confidence in Financial Knowledge is the sum of the confidence scores following each financial knowledge question. Participants report their confidence in their answer after each question on a scale of extremely confident (3), fairly confident (2), a little confident (1), or not at all confident (0). Overconfidence is measured as the sum of the confidence scores for questions answered incorrectly. Age and Education are stated in years. Male is an indicator variable that equals one for male participants and zero for female participants.

\begin{tabular}{|c|c|c|c|c|c|c|c|c|c|}
\hline & 1 & 2 & 3 & 4 & 5 & 6 & 7 & 8 & 9 \\
\hline Overconfidence & $\begin{array}{l}0.065 * * \\
(0.029)\end{array}$ & $\begin{array}{l}0.056 * * \\
(0.028)\end{array}$ & $\begin{array}{l}0.053^{*} \\
(0.029)\end{array}$ & - & - & - & - & - & - \\
\hline $\begin{array}{l}\text { Financial } \\
\text { Knowledge }\end{array}$ & - & - & - & $\begin{array}{l}-0.090 \\
(0.065)\end{array}$ & $\begin{array}{l}-0.028 \\
(0.065)\end{array}$ & $\begin{array}{l}-0.018 \\
(0.066)\end{array}$ & - & - & - \\
\hline Confidence & - & - & - & - & - & - & $\begin{array}{l}0.012 \\
(0.021)\end{array}$ & $\begin{array}{l}0.034 \\
(0.022)\end{array}$ & $\begin{array}{l}0.032 \\
(0.021)\end{array}$ \\
\hline Age & $\begin{array}{l}- \\
0.057 * * * \\
(0.014)\end{array}$ & - & - & $\begin{array}{l}- \\
0.059 * * * \\
(0.014)\end{array}$ & - & - & $\begin{array}{l}0.054^{* * *} \\
(0.014)\end{array}$ & - & - \\
\hline Male & - & $\begin{array}{l}-0.121 \\
(0.269)\end{array}$ & - & - & $\begin{array}{l}-0.124 \\
(0.277)\end{array}$ & - & - & $\begin{array}{l}-0.295 \\
(0.282)\end{array}$ & - \\
\hline Education & - & - & $\begin{array}{l}-0.025 \\
(0.038)\end{array}$ & - & - & $\begin{array}{l}-0.037 \\
(0.039)\end{array}$ & - & - & $\begin{array}{l}-0.052 \\
(0.039)\end{array}$ \\
\hline Intercept & $\begin{array}{l}2.300^{* *} \\
(1.106)\end{array}$ & $\begin{array}{l}- \\
2.235 * * * \\
(0.187)\end{array}$ & $\begin{array}{l}1.871^{* * *} \\
(0.628)\end{array}$ & $\begin{array}{l}3.307 * * * \\
(1.268)\end{array}$ & $\begin{array}{l}- \\
1.805^{* * *} \\
(0.411)\end{array}$ & $\begin{array}{l}-1.338^{* *} \\
(0.619)\end{array}$ & $\begin{array}{l}2.108^{*} \\
(1.267)\end{array}$ & $\begin{array}{l}- \\
2.590 * * * \\
(0.424)\end{array}$ & $\begin{array}{l}- \\
1.838 * * * \\
(0.646)\end{array}$ \\
\hline
\end{tabular}




\section{Table 6: Summary Statistics for After Fraud Sample}

This table presents summary statistics for the after fraud sample as well as for a breakdown into those participants who experienced fraud and those who did not. Financial Risk Taking is the participants' assessment of their willingness to take risks in financial matters on a scale from not at all willing (1) to completely willing (10) to take risks. Accept $10 \%$ Income Gamble indicates that the participant would be willing to accept a gamble with a 50\% chance of doubling annual income and a 50\% chance of cutting it by $10 \%$. Accept $20 \%$ Income Gamble indicates that the participant would be willing to accept a gamble with a 50\% chance of doubling annual income and a 50\% chance of cutting it by 20\%. Values are reported as means (standard deviation) or percentages.

\begin{tabular}{|c|c|c|c|}
\hline Fraud Victims (59) & Before & After & Change \\
\hline Financial Risk Taking & $4.76(1.99)$ & $4.84(2.01)$ & $0.08(1.47)$ \\
\hline $\begin{array}{l}\text { Accept } 10 \% \text { Income } \\
\text { Gamble }\end{array}$ & $12 \%$ & $29 \%$ & $17 \%$ \\
\hline $\begin{array}{l}\text { Accept } 20 \% \text { Income } \\
\text { Gamble }\end{array}$ & $12 \%$ & $7 \%$ & $-5 \%$ \\
\hline Not Fraud Victims (536) & Before & After & Change \\
\hline Financial Risk Taking & $4.88(2.11)$ & $4.68(2.15)$ & $-0.20(2.19)$ \\
\hline $\begin{array}{l}\text { Accept } 10 \% \text { Income } \\
\text { Gamble }\end{array}$ & $20 \%$ & $20 \%$ & $0 \%$ \\
\hline $\begin{array}{l}\text { Accept } 20 \% \text { Income } \\
\text { Gamble }\end{array}$ & $8 \%$ & $7 \%$ & $-1 \%$ \\
\hline
\end{tabular}




\section{Table 7: Change in Risk Taking After Fraud}

This table presents mean changes in risk taking among fraud victims and those not victimized. The propensity-matched difference compares each fraud victim's change in risk taking to the non-victim's change who had the closest fraud propensity score as the victim. Fraud propensity is estimated using Model 1 in Table 5. Financial Risk Taking is the participants' assessment of their willingness to take risks in financial matters on a scale from not at all willing (1) to completely willing (10) to take risks. Accept 10\% Income Gamble indicates that the participant would be willing to accept a gamble with a 50\% chance of doubling annual income and a 50\% chance of cutting it by $10 \%$. Accept 20\% Income Gamble indicates that the participant would be willing to accept a gamble with a 50\% chance of doubling annual income and a 50\% chance of cutting it by $20 \%$.

\begin{tabular}{|c|c|c|c|c|}
\hline Change in: & $\begin{array}{l}\text { Fraud } \\
\text { Victim } \\
\end{array}$ & $\begin{array}{l}\text { Not Fraud } \\
\text { Victim } \\
\end{array}$ & Difference in Means & $\begin{array}{l}\text { Propensity-Matched } \\
\text { Difference }\end{array}$ \\
\hline Financial Risk Taking & $\begin{array}{l}0.085 \\
(0.191)\end{array}$ & $\begin{array}{l}-0.198^{* *} \\
(0.095)\end{array}$ & $\begin{array}{l}0.283 \\
(0.213)\end{array}$ & $\begin{array}{l}0.847 * * \\
(0.383)\end{array}$ \\
\hline Accept $10 \%$ Income Gamble & $\begin{array}{l}17 \% * * * \\
(6 \%)\end{array}$ & $\begin{array}{l}0 \% \\
(2 \%)\end{array}$ & $\begin{array}{l}16 \% * * \\
(6 \%)\end{array}$ & $\begin{array}{l}22 \% * * \\
(9 \%)\end{array}$ \\
\hline Accept $20 \%$ Income Gamble & $\begin{array}{l}-5 \% \\
(4 \%)\end{array}$ & $\begin{array}{l}-1 \% \\
(1 \%)\end{array}$ & $\begin{array}{l}-4 \% \\
(5 \%)\end{array}$ & $\begin{array}{l}-2 \% \\
(5 \%)\end{array}$ \\
\hline
\end{tabular}

** and $* * *$ indicate statistically significant at the $5 \%$, and $1 \%$ level respectively 


\section{Appendix A: Cognition Tests}

The global cognition score is calculated by converting raw scores on each of the 19 tests listed below to $\mathrm{z}$ scores, using the mean and standard deviation from the full cohort at baseline, and then averaging the $\mathrm{z}$ scores to produce the composite measure. The composite measure of each cognitive domain is calculated similarly using only the tests in that domain.

\section{Episodic Memory}

1. Logical memory (immediate) Story A from the Logical Memory subset of the Wechsler Memory Scale-Revised

2. Logical memory (delayed) Story A from the Logical Memory subset of the Wechsler Memory Scale-Revised

3. CERAD Word list recall (immediate)

4. CERAD Word list recall (delayed)

5. CERAD Word list recognition

6. East Boston Story (immediate)

7. East Boston Story (delayed)

Perceptual Speed

1. Oral version of the Symbol Digit Modalities Test

2. Number Comparison

3 and 4.2 indices from a modified version of the Stroop Neuropsychological Screening test

\section{Semantic Memory}

1. Verbal fluency from CERAD

2. 15 item version of the Boston Naming Test

3. 15-item reading test

Visuospatial Ability

1. 15-item version of Judgment of Line Orientation

2. 16-item version of Standard Progressive Matrices 
Working Memory

1. Digit Span subtests-forward of the Wechsler Memory Scale-Revised

2. Digit Span subtests-backward of the Wechsler Memory Scale-Revised

3. Digit Ordering 


\section{Appendix B: Decision-Making Survey Questions}

\section{Financial Fraud Question}

In the past year, were you a victim of financial fraud or have you been told you were a victim of financial fraud?

\section{Scam Susceptibility Questions}

Note: The next five questions each include the following answer choices: strongly agree, agree, slightly agree, neither agree nor disagree, slightly disagree, disagree, strongly disagree.

1. I answer the phone whenever it rings, even if I do not know who is calling.

2. I have difficulty ending a phone call, even if the caller is a telemarketer, someone I do not know, or someone I did not wish to call me.

3. If something sounds too good to be true, it usually is.

4. Persons over the age of 65 are often targeted by con-artists.

5. If a telemarketer calls me, I usually listen to what they have to say.

6. Are you listed on the national do not call registry? Yes or No?

Financial Knowledge and Confidence Questions

Note: Each financial knowledge question is followed by the same confidence question below. How confident are you that you answered that question correctly? extremely confident, fairly confident, a little confident, not at all confident

1. What do the initials FDIC stand for? 
2. What does the FDIC do?

approves new drugs for clinical use, protects the funds people or depositors place in banks and savings institutions, underwrites mortgages and other loans

3. A mutual fund is an investment that holds what---only stocks, only bonds, or stocks AND bonds?

4. When interest rates go up, what do bond prices do: go down, go up, or stay the same?

5. True or false. Buying a single company stock usually provides a better return than a stock mutual fund.

6. True or False. An older person with $\$ 100,000$ to invest should hold riskier financial investments than a younger person with $\$ 100,000$ to invest.

7. True or False. Using money in a bank account to pay off credit card debt is usually wise.

8. True or False. To make money in the stock market, you have to buy and sell stocks often.

9. True or False. Stocks and mutual funds generally produce higher average returns above inflation compared to fixed-income investments such as bonds.

\section{Financial Risk Taking Question}

Using this 1-10 point rating scale, where 1 indicates that you are not at all willing to take risks and 10 indicates that you are completely willing to take risks, what would you say has been over your lifetime your willingness to take risks in financial matters?

\section{Income Gamble Questions}

1. Suppose that the chances were 50-50 that the investment opportunity would double your annual income and $50-50$ that it would cut it by $1 / 10$ or $10 \%$ ? Would you take the risk? 
2. Suppose that the chances were 50-50 that the investment opportunity would double your annual income and $50-50$ that it would cut it by $1 / 5$ or $20 \%$ ? Would you take the risk? 


\section{RECENT WORKING PAPERS FROM THE CENTER FOR RETIREMENT RESEARCH AT BOSTON COLLEGE}

New Evidence on the Risk of Requiring Long-Term Care

Leora Friedberg, Wenliang Hou, Wei Sun, Anthony Webb, and Zhenyu Li, November 2014

SSI at 62: Protecting the Vulnerable When Increasing Social Security's Early Entitlement Age

Norma B. Coe and April Yanyuan Wu, June 2014

Why Do SSI and SNAP Enrollments Rise in Good Economic Times and Bad?

Matthew S. Rutledge and April Yanyuan Wu, June 2014

The Impact of Mandatory Coverage on State and Local Budgets

Alicia H. Munnell, Jean-Pierre Aubry, and Anek Belbase, May 2014

Interest Rates and Economic Growth: Are They Related?

Barry P. Bosworth, May 2014

The Tradeoff Between Health and Wealth in Retirement Decisions

Kristine M. Brown, May 2014

The Effect of Increasing Earnings Dispersion on Social Security Payroll Tax Receipts Richard Kopcke, Zhenyu Li, and Anthony Webb, May 2014

What Impact Does Social Security Have on the Use of Public Assistance Programs Among the Elderly?

Norma B. Coe and April Yanyuan Wu, May 2014

Differential Mortality and Retirement Benefits in the Health and Retirement Study Barry P. Bosworth and Kathleen Burke, April 2014

Adding Employer Contributions to Health Insurance To Social Security's Earnings and Tax Base

Karen E. Smith and Eric Toder, April 2014

Lower-Income Individuals Without Pensions: Who Misses Out and Why?

April Yanyuan Wu and Matthew S. Rutledge, March 2014

How Do Subjective Longevity Expectations Influence Retirement Plans?

Mashfiqur R. Khan, Matthew S. Rutledge, and April Yanyuan Wu, January 2014

All working papers are available on the Center for Retirement Research website (http://crr.bc.edu) and can be requested by e-mail (crr@bc.edu) or phone (617-552-1762). 